\title{
Coinfection of Enteric Viruses in Elderly Patients with and without Acute Gastroenteritis in Hilla City
}

\author{
Dalalabdulkareem ${ }^{1}$, Ghanim Aboud Jaber Al-Mola ${ }^{2}$ \\ ${ }^{1}$ M.Sc. Student, University of Babylon, College of Science for Women, Dept. of Biology, \\ ${ }^{2}$ Prof. Dr., University of Babylon, College of Science for Women, Dept. of Biology
}

\begin{abstract}
This study was conducted to find out the extent of the presence of mixed viral infections for elderly people with and without acute enteritis. 100 stool samples were collected, 50 samples of which were for people with acute enteritis and the other 50 samples were from non-infected people. These mixed infections were obtained within the group of infected patients, where the age group 45-49 was the most infected and then the sample was prepared by making several treatments For the purpose of performing the PCR molecular test. As the results of this test indicated that 15 samples contain Astrovirus from the total number of samples. And 7 samples containing norovirus from the total number of samples. while the test recorded 10 samples containing the sapovirus from the total number of samples. The study showed that the relationship between acute gastroenteritis and gender revealed that male infection is close to female infection, as there is no significant difference between them. In regard to mixed infection the study showed that the number of samples infected with Rota, Adeno, and Astro viruses was 4 positive samples, while the number of samples containing Rota adenonoro is only one positive sample is the same as the number of samples containing only Astro and Noro that were recorded as a result of acute enteritis. The results also indicated that three coinfection positive samples of rota, adeno and sapo. As tested by Rapid test and PCR technique.
\end{abstract}

Keywords: Coinfection, norovirus, sapovirus, elderly.

\section{Introduction}

Acute gastrointestinal is one of the most common diseases in humans, and continues to be a significant cause of mortality and morbidity worldwide. Recently the estimates of mortality associated with diarrhea declined, however the majority of deaths still occur in developing countries and thus urgent intervention is needed for the prevention of these diseases. The incidence of acute gastrointestinal infection rises in the aged group under five years and in those aged over 75 . At all ages incidence in men was higher than in women in elderly patients ${ }^{1}$. The common enteroviral infection rotavirus, adenovirus, astrovirus, norovirus and sapovirus the most common etiology of acute gastroenteritis (AGE) among infants and young children. Acute gastrointestinal symptomatology_including diarrhea andnausea/ vomiting - in patients ${ }^{2}$. Rotaviruses are non-enveloped double-stranded RNA (dsRNA) viruses that have a complex architecture of three concentric capsids that surround a genome of 11 segments of dsRNA ${ }^{3}$. Human adenoviruses (HAdVs) are nonenveloped, doublestranded DNA viruses in the family Adenoviridae; seven species $(A-G)$ and $>60$ genotypes are known to cause human infection ${ }^{4}$. Astroviruses are nonenveloped, positive-sense single-stranded RNA viruses that cause gastrointestinal illness ${ }^{5}$. Human noroviruses have a non-segmented positive- strand RNA genome, of approximately $7.5 \mathrm{~kb}^{6}$. Sapovirus, a member of the Caliciviridae family, is a single-stranded positive sense RNA virus, with 4 genogroups, that infect humans ${ }^{7}$.

\section{Materials and Method}

During a period (from suptember 2019 to January 2020) 100 stool sample from adults (equal to or more than 45 years) who were hospitalised with or without acute gastroenteritis (AGE) their primary diagnosis for in interic virus from four hospitals in the Babil Governorate Region with a total population of 18000,000 people. 
These samples were taken from (Imam Sadiq Hospital, Al-Kifl Hospital, Margan Hospital and Hashemia Hospital).

Stool samples were collected in clean sterile containers within 48 hours of admission. Each sample was labeled according to the date of collection and the sample number. The samples were kept at $4^{\circ} \mathrm{C}$ at the hospital before being transported to the College.

Rapid test of Rotavirus and Adenovirus (Zaragoza, Spain), stool samples and controls to reach room temperature(15-30) prior to testing. The test performed according to company instructions.

Viral RNA was extracted from stool samples by using AccuZol ${ }^{\mathrm{TM}}$ Total RNA extraction kit (Bioneer, usa) and done according to company instructions.

PCR test.

PCR was performed for molecular detection of virus based on core protein. This method was done according to ${ }^{8}$.

PCR master mix was prepared by using (AccuPower ${ }^{\circledR}$ PCR PreMix) and done according to the company instructions.
The PCR primers used for direct detection of Norovirus, Astrovirus and Saprovirus were designed by $^{9}$ and PCR primers were designed in this study using NCBI Database and primer 3 plus and these primers were provided by (Macrogen. Company, Korea)

\section{Result and Discussion}

The total positivly rate of combined viral infection in elderly patient with acute gastrointestnal infection in relation to age.

Among the 50 samples collecteal from elderly individuals patient with gastrointestnal symptoms the age distribution ofpositivly rate of viral infection(rotavvirus, adenovirus, astrovirus, norovirus and sapovirus) infections was detected in the age group 45-49 years were 12 at $24 \%$ for each rotavirus and adenovirus while astrovirusrecoreded 6 at $12 \%$ and norovirusrecoreded 2 at $4 \%$ followed by 9 at $18 \%$ for rotavirus and adinovirus while astrovirus has 5 at $10 \%$ The norovirus has 2 at $4 \%$ sapovirus has one infected at $2 \%$ at the age group 50-54. At The age groups 55-59, 60-64 and 65-69 years show 6, 2 and 1 for every rotavirus and adinovirus respectively at a percentage $12 \%, 4 \%$ and $2 \%$ while astrovirus has 1 at $2 \%$ At The age groups 55-59, sapovirusrecored one infected for each these group 55-59 65-69 and 70-74 at $2 \%$ (table 1).

Table 1. The total of positivly rate of poly- viral infection in elderly patient with acute gastrointestnal infection in relation to age.

\begin{tabular}{|l|c|c|c|c|c|c|c|c|c|c|}
\hline \multirow{2}{*}{$\begin{array}{l}\text { Age } \\
\text { groups }\end{array}$} & \multicolumn{2}{|c|}{ Rotavirus } & \multicolumn{2}{c|}{ Adenovirus } & \multicolumn{2}{c|}{ Astrovirus } & \multicolumn{2}{c|}{ Norovirus } & \multicolumn{2}{c|}{ Sapopvirus } \\
\cline { 2 - 12 } & No. & $\mathbf{\%}$ & No. & $\mathbf{\%}$ & No. & $\mathbf{\%}$ & No. & $\%$ & No. & \% \\
\hline $45-49$ & 12 & $24 \%$ & 12 & $24 \%$ & 6 & $12 \%$ & 2 & $4 \%$ & Nil & Nil \\
\hline $50-54$ & 9 & $18 \%$ & 9 & $18 \%$ & 5 & $10 \%$ & 2 & $4 \%$ & 1 & $2 \%$ \\
\hline $55-59$ & 6 & $12 \%$ & 6 & $12 \%$ & 1 & $2 \%$ & Nil & Nil & 1 & $2 \%$ \\
\hline $60-64$ & 2 & $4 \%$ & 2 & $4 \%$ & Nil & Nil & Nil & Nil & Nil & Nil \\
\hline $65-69$ & 1 & $2 \%$ & 1 & $2 \%$ & Nil & Nil & Nil & Nil & 1 & $2 \%$ \\
\hline $70-74$ & Nil & Nil & Nil & Nil & Nil & Nil & Nil & Nil & 1 & $2 \%$ \\
\hline$\geq 75$ & Nil & Nil & Nil & Nil & Nil & Nil & Nil & Nil & Nil & Nil \\
\hline Total & $\mathbf{3 0}$ & $\mathbf{6 0} \%$ & $\mathbf{3 0}$ & $\mathbf{6 0} \%$ & $\mathbf{1 2}$ & $\mathbf{2 4 \%}$ & $\mathbf{4}$ & $\mathbf{8 \%}$ & $\mathbf{4}$ & $\mathbf{8 \%}$ \\
\hline
\end{tabular}

$*$ p_value $\leq 8.34$

The total positivly rate of combined viral infection in elderly patient with acute gastrointestnal infection in relation to sex.
The results of relation between occurence of AGI and gender shown that the positive among male 13 of patients AGI for every rotavirus and adeno virus at 
$26 \%$, astrovirus has 9 at $18 \%$, norovirus has 3 at $6 \%$ and sapovirus has 2 at $4 \%$ while female the positive were 16 of patients AGI for rotavirus and adino virus at
$32 \%$, astrovirus has 2 at $4 \%$, norovirus has 1 at $2 \%$ and sapovirus has 2 at $4 \%$ (table 2)

Table 2. The total positivly rate of poly-viral infection in elderly patient with acute gastrointestnal infection in relation to sex.

\begin{tabular}{|l|c|c|c|c|c|c|c|c|c|c|}
\hline \multirow{2}{*}{ Gander } & \multicolumn{2}{|c|}{ Roravirus } & \multicolumn{2}{c|}{ Adinovirus } & \multicolumn{2}{c|}{ Astrovirus } & \multicolumn{2}{c|}{ Norovirus } & \multicolumn{2}{c|}{ Sapopvirus } \\
\cline { 2 - 11 } & $\mathbf{N o}$ & $\mathbf{\%}$ & No. & $\mathbf{\%}$ & No. & $\mathbf{\%}$ & No. & $\%$ & No. & $\%$ \\
\hline Male & 13 & $26 \%$ & 13 & $26 \%$ & 9 & $18 \%$ & 3 & $6 \%$ & 2 & $4 \%$ \\
\hline Female & 16 & $32 \%$ & 16 & $32 \%$ & 2 & $4 \%$ & 1 & $2 \%$ & 2 & $4 \%$ \\
\hline Total & $\mathbf{2 9}$ & $\mathbf{5 8 \%}$ & $\mathbf{2 9}$ & $\mathbf{5 8 \%}$ & $\mathbf{1 1}$ & $\mathbf{2 2} \%$ & $\mathbf{4}$ & $\mathbf{8 \%}$ & $\mathbf{4}$ & $\mathbf{8 \%}$ \\
\hline
\end{tabular}

$*$ p_value $\leq 9.11$

Viruses infect host cells releasing their genome (DNA or RNA) containing all information needed to replicate themselves. The viral genome takes control of the cells and helps the virus to evade the host immune syste $^{10}$.

Infectious diarrhea is an important cause of morbidity and mortality among the elderly in the United States. The full scope of its impact has been recognized more in recent years ${ }^{11}$ can be life threatening in an elderly immunocompetent individual. The whole gastrointestinal tract can be affected by viral, however, small bowel was rarely the only site of disease, In elderly individuals, even though they are immunocompetent, may result in major complications such as bowel perforation, and it should be included in the differential diagnosis of diarrhea if it is resistant to conventional treatment ${ }^{21}$. Acute diarrheal illness is a global health problem that causes immense human misery. Military history is testament to the overwhelming power of acute diarrheal illness: Napoleon Bonaparte's army, soldiers of the American Civil War, and German forces of World War II were pillaged by enteric infections. The French Expeditionary Force to Indochina was stricken with many enteric infections. These infections hampered military efforts and were deemed to have played a pivotal role in military defeats. The significance of enteric infection in military campaigns contributed to the US Army's surgeon general's decision to establish a team to assess the magnitude and to determine the cause of diarrheal outbreaks among American troops in Vietnam. With the exception of fevers of undetermined origin, diarrheal diseases were responsible for more hospital admissions than any other diseases ${ }^{13}$. The total positivly rate of combined viral infection in heathy elderly individuals in relation to age. Among the 50 samples collected from elderly individuals without acute gastrointestinal infection the age distribution of positivly rate of viral infection(rotavirus, adenovirus, astrovirus, norovirus and sapovirus) infections was detcated in the age group 45-49 years only astrovirusrecored 2 at $4 \%$ while astrovirus and norovirus have 1 at $2 \%$ at the age group 50-54. At The age groups 55-59 for aeah one astrovirus and sapovirus have only one infected at $2 \%$ while in this age group norovirusrecored tow infected at $4 \%$ when sapovirusrecored one infection at $2 \%$ at age group 70-74 (table 3).

Table 3. The frequency of total positivly rate of polyviral infection in heathy elderly individuals in relation to age

\begin{tabular}{|l|c|c|c|c|c|c|c|c|c|c|}
\hline \multirow{2}{*}{$\begin{array}{l}\text { Age } \\
\text { goup }\end{array}$} & \multicolumn{2}{|c|}{ Roravirus } & \multicolumn{2}{c|}{ Adinovirus } & \multicolumn{2}{c|}{ Astrovirus } & \multicolumn{2}{c|}{ Norovirus } & \multicolumn{2}{c|}{ Sapopvirus } \\
\cline { 2 - 12 } & No. & \% & No. & \% & No. & \% & No. & \% & No. & \% \\
\hline $45-49$ & Nil & Nil & Nil & Nil & 2 & $4 \%$ & Nil & Nil & Nil & Nil \\
\hline $50-54$ & Nil & Nil & Nil & Nil & 1 & $2 \%$ & 1 & $2 \%$ & Nil & Nil \\
\hline $55-59$ & Nil & Nil & Nil & Nil & 1 & $2 \%$ & 2 & $4 \%$ & 1 & $2 \%$ \\
\hline$\geq 64$ & Nil & Nil & Nil & Nil & Nil & Nil & Nil & Nil & 1 & $2 \%$ \\
\hline Total & Nil & Nil & Nil & Nil & $\mathbf{4}$ & $\mathbf{8 \%}$ & $\mathbf{3}$ & $\mathbf{6 \%}$ & $\mathbf{2}$ & $\mathbf{4 \%}$ \\
\hline
\end{tabular}

$*$ p_value $\leq 1.29$ 
The total positivly rate of combined viral infection in heathy elderly individuals in relation to sex.

The results of relation between occurence of wethout AGI and gender shown that the positive among male astrovirus has 3 at $6 \%$, norovirus has 2 at $4 \%$ and sapovirus has 3 at $6 \%$ while female the positive were astrovirus and norovirus have 1 at $2 \%$ for every one and sapovirus has 3 at $6 \%$ (table 4$)$.

Table 4. The distribution of total positivly rate of viral infection in heathy elderly individuals in relation to sex.

\begin{tabular}{|l|c|c|c|c|c|c|c|c|c|c|}
\hline \multirow{2}{*}{ Gander } & \multicolumn{2}{|c|}{ Roravirus } & \multicolumn{2}{c|}{ Adenovirus } & \multicolumn{2}{c|}{ Astrovirus } & \multicolumn{2}{c|}{ Norovirus } & \multicolumn{2}{c|}{ Sapopvirus } \\
\cline { 2 - 12 } & No. & $\mathbf{\%}$ & No. & $\mathbf{\%}$ & No. & $\mathbf{\%}$ & No. & $\%$ & No. & $\%$ \\
\hline Male & Nil & Nil & Nil & Nil & 3 & $6 \%$ & 2 & $4 \%$ & 3 & $6 \%$ \\
\hline Female & Nil & Nil & Nil & Nil & 1 & $2 \%$ & 1 & $2 \%$ & 3 & $6 \%$ \\
\hline Total & Nil & Nil & Nil & Nil & $\mathbf{4}$ & $\mathbf{8 \%}$ & $\mathbf{3}$ & $\mathbf{6 \%}$ & $\mathbf{6}$ & $\mathbf{1 2 \%}$ \\
\hline
\end{tabular}

*p_value $\leq 1.48$

Some viruses alter the functions of infected cells without killing them. In some cases infected cells lose control over normal cell proliferation and becomes cancerous. Viruses, may leave their viral genome in the host cells for a certain period (latency) and begin to replicate when the cells are stressed causing diseases. have developed multiple strategies to avoid recognition and elimination by the host's immune system. These strategies rely on viral products that mimic specific components of the host cells to prevent immune recognition of virally infected cells. In addition to viral proteins, viruses encode short non-coding RNAs (vmiRNAs) that regulate both viral and host cellular transcripts to favor viral infection and actively curtail the host's antiviral immune response. ${ }^{10}$
Adults more than 65 years of age were the age group most commonly affected ${ }^{18}$.

The mixed viral infection in elderly individuals with and without acute gastrointestinal infection

This figure showed the mixed viral infecion in 100 sample colected from elderly individuals with and without symptoms. The mixed infection were found between rotavirus, adenovirus and astrovirus were more dominae at $4 \%$ followed by rotavirus, adinovirus and sapovirus 3\%.Then rotavirus, adinovirus and norovirus $1 \%$, and the double infection were noticed between astrovirus and norovirus at $1 \%$ (Figure $4-1$ ).

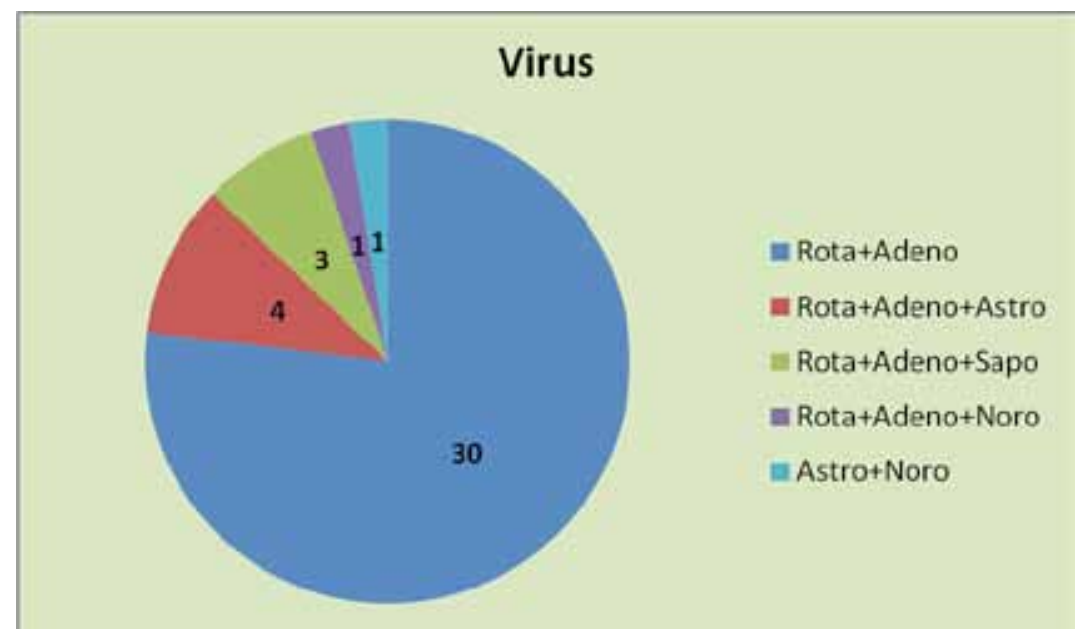

Figure (1) The distribution mixed viral infection in elderly individuals with and without acute gastrointestinle infection. 
This could be explained by a close-knit family environment where the elderly frequently look after their grandchildren, Vomiting was, thus, associated with viral pathogens. Various factors influence symptoms and signs, including pathogen and host factors, infectious load, and mixed infections. The English re-examination study showed that about $40 \%$ of symptomatic patients harbored mixed infections the occurrence of mixed infections suggests that a wide test panel should be applied in some cases, such as for food handlers. Selective testing is necessary for cost efficiency and is widely practiced ${ }^{19}$. Antibodies were found in $10 \%$ of serum samples from the aged. Of patients with acute gastroenteritis,showed a significant rise in antibody to adenovirus, and of the same serum samples had a significant rise in antibody to rotavirus by enzyme immunoassay ${ }^{20}$. The PCR results of stool sample from acutgastrointestin infection showed that the produce analysis Astrovirus form exacerbated RNA stool of patients with AGI positive for gives 15 sample with positive Astrovirus at 523bp PCR produce these results indicate the presences of Astrovirus during exacerbated of AGI while may indicated the chance of association with AGI.

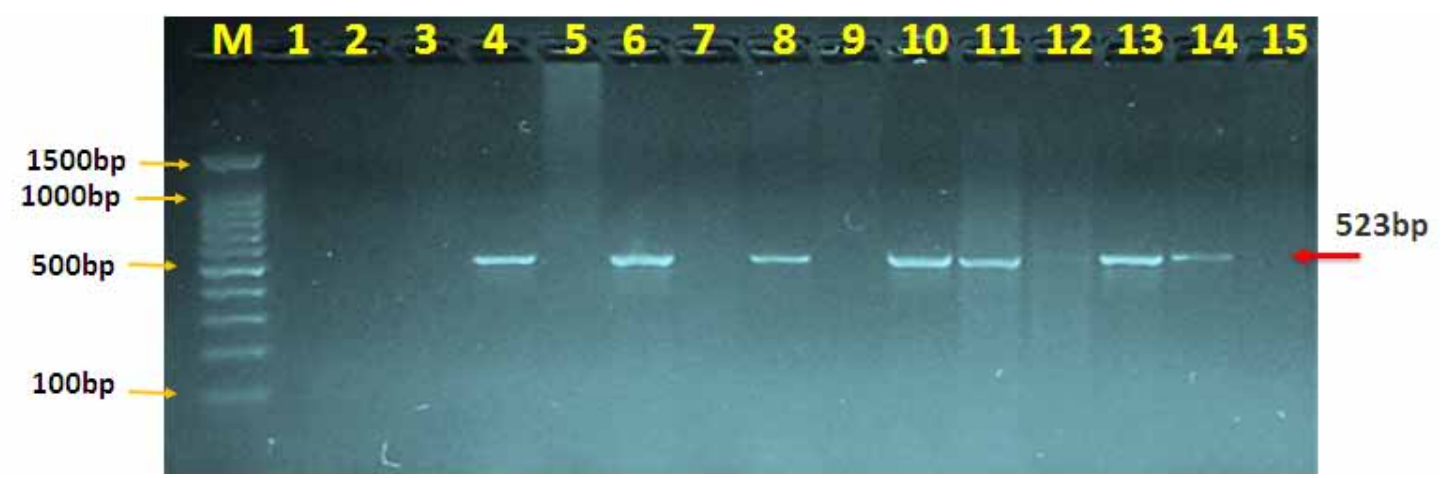

Figure (2): Agarose gel electrophoresis image that show the PCR product analysis of Astrovirus, where ladder (1500-100bp), some positive samples at (523bp) PCR product.

The PCR results of stool sample from acutgastrointestin infection showed that the produce analysis Norovirus form exacerbated RNA stool of patients with AGI positive for gives 7 sample with positive Astrovirus at 560bp PCR produce these results indicate the presences of Norovirus during exacerbated of AGI while may indicated the chance of association with AGI.

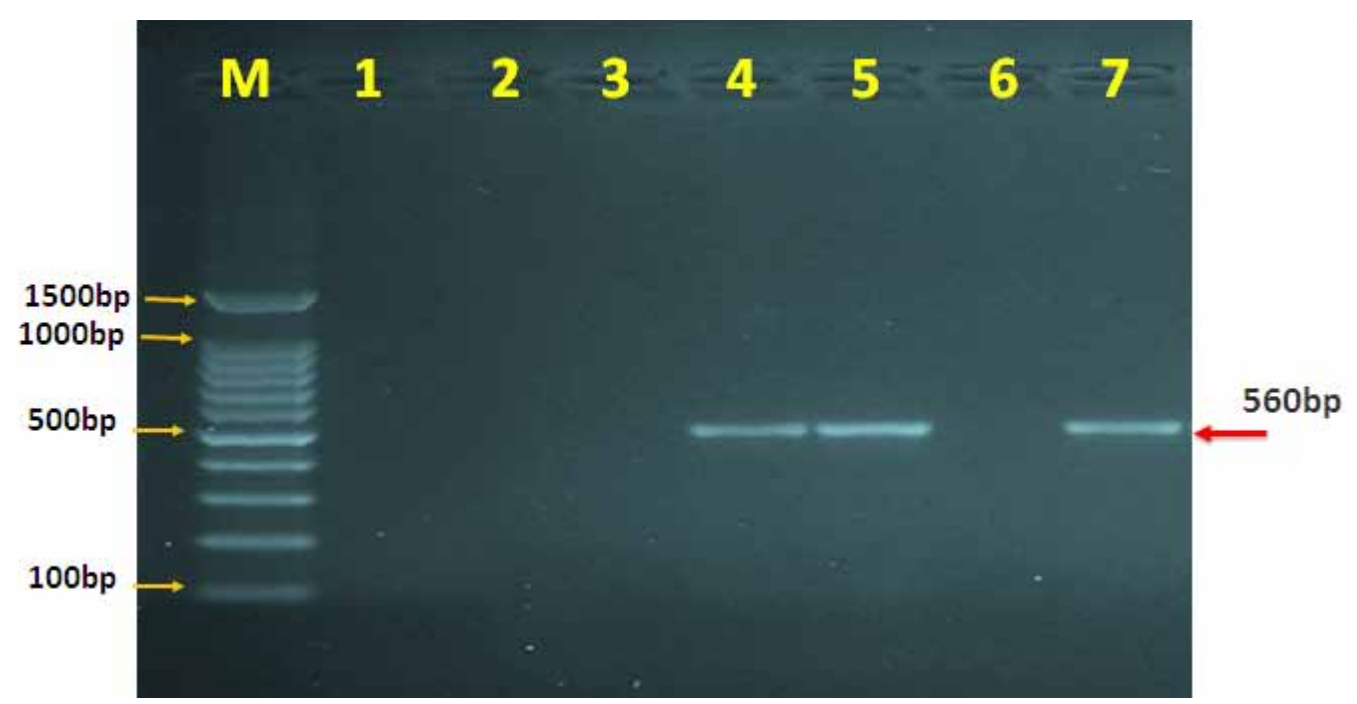

Figure (3): Agarose gel electrophoresis image that show the PCR product analysis of Norovirus, where ladder (1500-100bp), some positive samples at (560bp) PCR product. 
The PCR results of stool sample from acutgastrointestin infection showed that the produce analysis Sapovirus form exacerbated RNA stool of patients with AGI positive for gives 10 sample with positive Sapovirus at $401 \mathrm{bp}$ PCR produce these results indicate the presences of Sapovirus during exacerbated of AGI while may indicated the chance of association with AGI.

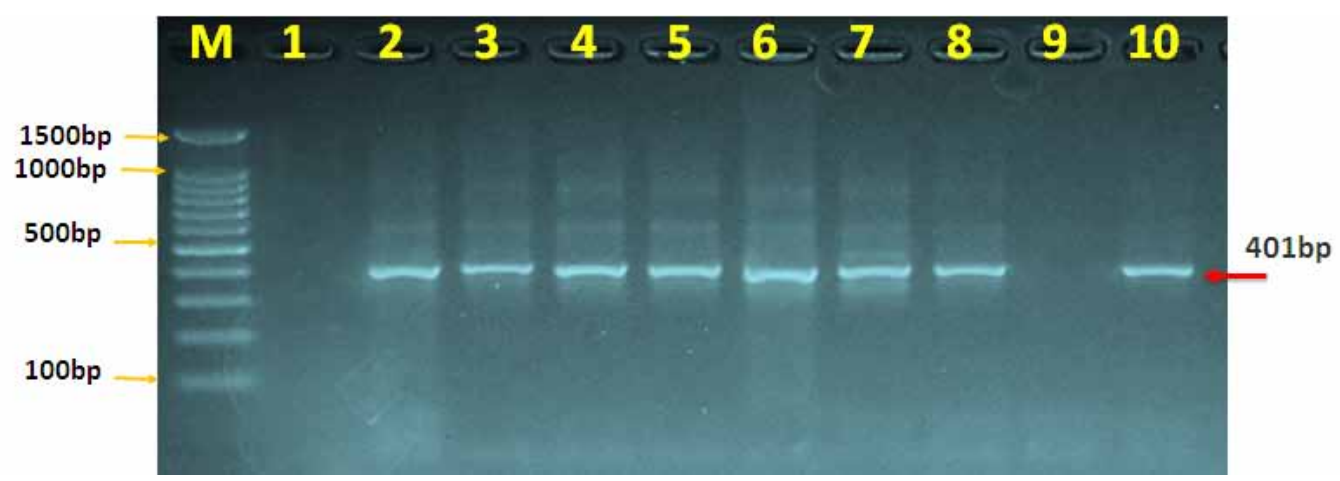

Figure (4): Agarose gel electrophoresis image that show the PCR product analysis of Saprovirus, where ladder (1500-100bp), some positive samples at (401bp) PCR product.

Sapovirus,astrovirus and Norovirus increasingly are recognized as cause of acute viral gastroenteritis (AGI). We evaluated the RT-PCR viral stool panel for detection of $\mathrm{SaV}, \mathrm{AstV}$ andNoV in clinical stool samples ${ }^{21}$.

A total of stools were tested using reverse transcription RT-PCR,PCR to detect and quantify SaV. And NoV were detected in many age groups, especially in the elderly. ${ }^{22}$.

Financial Disclosure: There is no financial disclosure.

Conflict of Interest: None to declare.

Ethical Clearance: All experimental protocols were approved under the University of Babylon and all experiments were carried out in accordance with approved guidelines.

\section{References}

1. Rockall TA, Logan R. Incidence of and mortality from acute upper gastrointestinal haemorrhage in the United Kingdom. Bmj.1995; 311(6999): 222226.

2. Nobel YR, Phipps M, Zucker J, Lebwohl B. Gastrointestinal symptoms and coronavirus disease 2019: a case-control study from the United States. Gastroenterology. 2020; 159(1), 373-375.

3. Crawford S, Ramani S, Tate JE. Rotavirus infection.
Nature Reviews Disease Primers. 2017; 3(1): 1-16.

4. Binder A, Biggs H, Haynes A. Human adenovirus surveillance-United States, 2003-2016. MMWR. Morbidity and mortality weekly report. 2017; 66(39): 1039.

5. Cortez V, Meliopoulos V, Karlsson EA. Astrovirus biology and pathogenesis. Annual review of virology. 2017; 4: 327-348.

6. deGraaf M, van Beek J, Koopmans MP. Human norovirus transmission and evolution in a changing world. Nature Reviews Microbiology. 2016; 14(7): 421-433.

7. Sánchez GJ, Mayta H, Pajuelo MJ, Neira K. Epidemiology of sapovirus infections in a birth cohort in Peru. Clinical Infectious Diseases.2018; 66(12): 1858-1863.

8. Durmaz OS. Türkiye'deöğretmenolmak: emeksüre civeyenidenproleterleşme. Nota Bene.2014.

9. Logan A, Martinez M, Wang M, Wu C, Ling, K. U.S. Patent Application No. 29/255: 998.2007.

10. Fruci D, Rota R, Gallo A. The role of HCMV and HIV-1 microRNAs: processing, and mechanisms of action during viral infection. Frontiers in microbiology.2017; 8: 689.

11. Slotwiner-Nie $P$, Brandt LJ. Infectious diarrhea in the elderly. Gastroenterology Clinics, 30(3), 625635.

12. Cha M, Haddadi H, Benevenuto F, Gummadi P. 
Measuring user influence in twitter: The million follower fallacy. Icwsm. 2010; 10(10-17): 30.

13. Ilnyckyj A. Clinical evaluation and management of acute infectious diarrhea in adults. Gastroenterology Clinics. 2001; 30(3): 599-609.

14. Guerrant R, Hughes JM. Diarrhea in developed and developing countries: magnitude, special settings, and etiologies. Reviews of infectious diseases. 1990; 12(1): S41-S50.

15. Zhang, Z., Lai, S., Yu, J., Geng, Q., Yang, W. Etiology of acute diarrhea in the elderly in China: A six-year observational study. PLoS One.2017; 12(3): e0173881.

16. Liu M, Li S, Shu Y, Zhan H. Probiotics for prevention of radiation-induced diarrhea: A metaanalysis of randomized controlled trials. PLoS One.2017; 12(6): e0178870.

17. $\mathrm{Vu} \mathrm{D,} \mathrm{Sabrià} \mathrm{A,} \mathrm{Aregall} \mathrm{N,} \mathrm{Michl} \mathrm{K.} \mathrm{Novel}$ Human Astroviruses: Prevalence and Association with Common Enteric Viruses in Undiagnosed Gastroenteritis Cases in Spain. Viruses.2019; 11(7): 585.

18. Pang $\mathrm{X}$, Lee B, Tyrrell G, Preiksaitis JK.
Epidemiology and genotype analysis of sapovirus associated with gastroenteritis outbreaks in Alberta, Canada: 2004-2007. The Journal of infectious diseases. 2009; 199(4): 547-551.

19. Hilmarsdóttir I, Baldvinsdottir GE. Enteropathogens in acute diarrhea: a general practice-based study in a Nordic country. European journal of clinical microbiology \& infectious diseases. 2012; 31(7): 1501-1509.

20. Shinozaki T, Araki K, Ushijima H, Fujii R. Antibody response to enteric adenovirus types 40 and 41 in sera from people in various age groups. Journal of clinical microbiology. 1987; 25(9): 1679-1682.

21. Redli PM, Wanzenried A, Huder JB. Evaluation of the RIDA ${ }^{\circledR}$ GENE RT-PCR assays for detection of sapovirus, astrovirus, adenovirus, and rotavirus in stool samples of adults in Switzerland. Diagnostic Microbiology and Infectious Disease. 2020; 96(2): 114924.

22. Varela MF, Rivadulla E, Lema A, Romalde J. Human sapovirus among outpatients with acute gastroenteritis in Spain: A one-year study. Viruses. 2019; 11(2): 144. 